Çukurova Üniversitesi Mühendislik Mimarlık Fakültesi Dergisi, 31(ÖS 1), ss. ÖS 35-ÖS 42, Ağustos 2016 Çukurova University Journal of the Faculty of Engineering and Architecture, 31(ÖS 1), pp. SI 35-SI 42, August 2016

\title{
Gemilerdeki Kaynaklı Yapılarda Isı Yalıtımı
}

\author{
Mehmet ŞAHIN $^{* 1}$, Yahya BOZKURT ${ }^{1}$ \\ ${ }^{1}$ Marmara Üniversitesi, Teknoloji Fakültesi Metalurji ve Malzeme Mühendisliği Bölümü, \\ Göztepe Kampüsü, Kadıköy / ISTANBUL
}

Geliş tarihi: 28.12.2015 Kabul tarihi: 30.03 .2016

\section{Özet}

Dünyada enerjinin verimli kullanılmasının gerekliliğine, insan konforu ve sağlı̆̆ı ile çevreye verilen öneme paralel olarak, yalıtım uygulamalarına verilen önem daha da artmıştır. Gemiler, yolcu ve çalışanların güvenliğini ve konforunu sağlamak, enerji tüketimini azaltmak, yatırım ve işletme maliyetlerini düşürmek, yoğuşma, terleme ve buzlanmayı önlemek amacıyla yalıtılırlar. Bunun yanında, taşınan malzemeleri korumak, geminin ağırlığını düşürüp kullanılan hacmi arttırmak, yapı elemanlarının ve sistemlerin ömürlerini uzatmak gibi amaçlarla da yalıtılmaktadırlar. Kaynaklı yapıdaki yalıtımın en önemli özelliklerden biri de yakıt tüketimini azaltarak çevreye atılan zararlı bileşenlerin miktarını düşürmektir.

$\mathrm{Bu}$ çalışmada, dünyada gemilerdeki kaynak üzerine yapılan 1sı yalıtımı uygulamaları hakkında yapılmış araştırmalar ve kullanılan yöntemler incelenmiş, uygulama detayları ve ülkemiz şartlarına uyarlanmış detaylar ve hesap değerleri irdelenmiştir. Çalışma, kapsamı itibariyle gemilerde 1s1 yalıtımı konusunda çalışacak araştırmacı ve tasarımcılara rehber olacak niteliktedir.

Anahtar Kelimeler: Gemilerde 1sı yalıtımı, Gemilerde kaynak, Yalıtım uygulamaları

\section{Thermal Insulation in Ships For Welding Structure}

\begin{abstract}
The importance of insulation applications in the world ascended in parallel with the necessity of the energy to be used efficiently, the significance that has been assigned to human comfort and environmental concerns. Ships are insulated for purposes such as maintaining the security and the comfort of the passengers and the crew, reducing energy consumption, reducing investment and operating costs, preventing condensation, sweating and freezing, protecting and conditioning cargo, decreasing the weight of the ship and increasing volume to be used, lengthening the physical life of the constructions and the systems, reducing the amount of emissions which has been thrown away by reducing fuel consumption, controlling noise and fire.

In this study, researches, studies and regulations worldwide about insulation of ships, applications have been analyzed welding, important parts have been gathered and selected, a guide was compiled, by using the application details, examples and calculation values which are adapted to our country's conditions. Considering its scope, this study has the characteristics of a guidebook for the researchers and designers who will work on the subject of thermal insulation of the ships.
\end{abstract}

Keywords: Thermal insulation in ships, Welding in ships, Insulation applications

\footnotetext{
* Sorumlu yazar (Corresponding author) : Yahya BOZKURT., Teknoloji Fakültesi, Metalurji ve Malzeme Mühendisliği Bölümü, Göztepe Kampüsü, Kadıköy / İstanbul. ybozkurt@marmara.edu.tr
} 


\section{GíRiş}

Society of Naval Architects and Marine Engineers (SNAME)'nin yayınlamış olduğu raporda gemilerde bulunan yap1 elemanlarında toplam 1S1 geçiş katsayısı değerlerine dair sınırlamalar getirilmiş, bir dizi test süreci ile elde edilmiş mukavemet elemanları tipi, yerleşimi, mevsim şartları, 1s1 akışı yönü gibi değişkenlere bağlı toplam 1sı geçiş katsayısı değerleri, detayları ile birlikte sunulmuştur. Bu yayında ayrıca gemilerde kullanılan çeşitli malzemelerin özellikleri ve mahaller arası 1sı geçişinin hesaplanmasında kullanılacak sıcaklık farkı değerleri de tablolar halinde verilmiştir. Yoğuşma ve terleme üzerine örnekler ile hesaplamalar anlatılmış, istenmeyen durumların engellenmesi için alınacak önlemlere yer verilmiştir [1].

$\mathrm{Bu}$ alanda yapılmış en önemli çalışmalardan bir diğeri de American Society of Testing and Materials, International (ASTM)'ın yayınlamış olduğu yönetmelikte, gemilerde tesisatın yalıtım yapılmasının gerekli olduğu yerler ve şartlar, kullanılacak 1s1 yalitım malzemeleri, uygulama kalınlıkları, uygulamada kullanılacak tespit elemanları, uygulama detayları kapsamlı olarak verilmiştir [2].

Bir diğer çalışma Amerikan Donanması, Askeri Deniz Ulaştırma Komutanlığı'nca yapılan çalışmada yukarı bahsi geçen iki kaynak temel alınmış ve üzerine bazı eklemeler yapılmıştır. Bunun yanında bu çalışma gemi elemanlarının ısı yalıtımı için sıcaklık farkı ve toplam 1sı geçiş katsayısı değerlerinin okunabileceği bir tablo içermektedir [3].

Bunun yanında Amerikan Denizcilik Bürosu (American Bureau of Shipping) tarafindan yayınlanmış "Gemilerde Yolcu Konforu" (Passanger Comfort on Ships) yönetmeliğinden gemilerdeki yaşama alanlarında sağlanması gereken isıl değerler alınmıştır. $\mathrm{Bu}$ değerler tasarım aşamasında dikkate alınıp örnekhesaplarda kullanılmıştır [4].

International Maritime Organisation (IMO) tarafından yayınlanmış International Convention on the Safety of Life at Sea (SOLAS) yönetmeliğinden, gemilerde kullanımına izin verilen, kısıtlı izin verilen ve tamamen izin verilmeyen malzemeler konusunda faydalanılmıştır [5].

Hart [6] ile Fulton ve arkadaşları [7] gemilerdeki bölme, kabuk ve güverte gibi yapısal elemanların yalıtılması üzerine çalışmalar yapmışlardır. $\mathrm{Bu}$ gemilerde çalışmalar 1sı yalıtımı konusu odaklı önem arzeden bilimsel makalelerdir [6,7]. Cox ve Curtin [7] gemilerde mekanik tesisat yalıtımının 3E Plus programı ile irdelenmesi temelli çalışmayla katkı sağlamıştır. Burton [9] gemilerde kullanılan yalıtım malzemelerine yanma sınıfları ile ilgili getirilen kısitlamaları konu alan bir çalışma yapmıştır. Mekanik tesisatın yalıtılması $[10,11]$, mukavemet elemanları üzerinden gerçekleşen 1S1 geçişi hesapları [12], illerdeki hesap sıcaklıkları ve nem değerleri ile yoğuşma, terleme ve buhar kesiciler konusunda çalışmışlar yapmışlardır $[13,14]$.

$\mathrm{Bu}$ çalışmada, tasarım ve hesaplarda kullanılması için Seyir, Hidrografi ve Oşinografi Dairesi Başkanlığı ve Meteoroloji Genel Müdürlüğü'nden deniz suyu tasarım sıcaklığı değerleri alınmıştır $[15,16]$. Gemilerin çelik gövdeleri ısı yalıtımı ile kaplanarak gemide 1sıtma ve soğutmada kullanılan enerji miktarını düşürmek, yolcular ve mürettebat için uygun ortam koşullarını ve güvenliği sağlamak, iç yüzeylerde yoğuşma ve terlemeyi önlemek, taşınan ya da depolanan malzemeleri, gıdaları, eşyaları korumak veya şartlandırmak, yangın yayılımını engellemek, gürültü ve akustik kontrolü yapmak, bazı hallerde ortamdaki nemi kontrol etmek üzerine yapılan çalışmalar irdelenmiştir.

\section{GEMILERDE ISI YALITIMINDA KULLANILAN MALZEME TÜRLERİ VE ÖZELLÍKLERİ}

\subsection{Cam Yünü}

İnorganik bir hammadde olan silis kumunun $1200^{\circ} \mathrm{C}-1250^{\circ} \mathrm{C}$ 'de ergitilerek elyaf haline getirilmesi sonucu oluşmaktadır. Şekil 1'de cam 
yünü gösterilmiştir. Camın kendisi kırılgan bir madde olduğu halde ince lifli türleri esnek, bükülebilen ve çok yönlü amaçlara hizmet edebilecek niteliktedir. Malzemenin lifleri arasındaki durgun hava 1sı geçiş direncini sağlamaktadır. Kullanım yeri ve amacına göre farklı boyut ve teknik özelliklerde, değişik kaplama malzemeleri ile şilte, levha, boru ve dökme şeklinde üretilebilmektedir. Isı yalıtımı, ses yalıtımı ve akustik düzenleme ile birlikte yangın güvenliği de sağlamaktadır. Alman Normu olan DIN 4102'ye ve Türk Standard1 TS EN 13501- 1'e göre yanmaz malzemeler olan A sınıfındandır. Isı iletkenlik değeri $0,040 \mathrm{~W} / \mathrm{mK}^{\prime}$ 'dır.
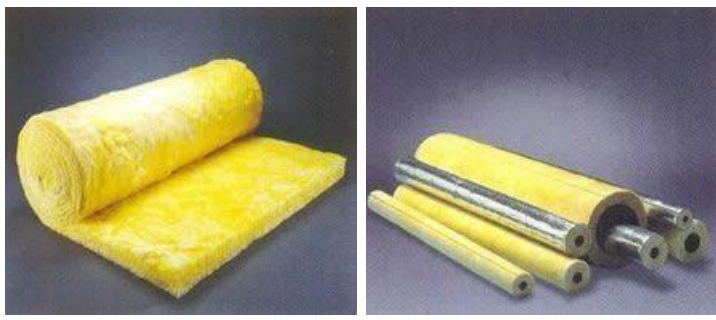

Şekil 1. Cam yünü [17]

$-200{ }^{\circ} \mathrm{C} /+500{ }^{\circ} \mathrm{C}$ aralığında kullanılan özel cam yünü ürünler üretilebilmektedir. Sicağa ve rutubete maruz kalması halinde boyutsal kararlığını korur. Zamanla bozulmaz, çürümez, küf tutmaz, korozyon ve pas yapmaz. Böcekler ve mikroorganizmalar tarafindan tahrip edilemez. Higroskopik ve kapiler değildir [17-19].

\subsection{Taş Yünü}

İnorganik bir hammadde olan bazalt taşının $1350^{\circ} \mathrm{C}-1400^{\circ} \mathrm{C}$ ' de ergitilerek elyaf haline getirilmesi sonucu oluşmaktadır (Şekil 2). Diğer çoğu elyaflı malzeme gibi malzemenin lifleri arasındaki durgun hava 1sı geçiş direncini sağlamaktadır. Kullanım yeri ve amacına göre farklı boyut ve teknik özelliklerde, değișik kaplama malzemeleri ile şilte, levha, boru ve dökme şeklinde üretilebilmektedir. Isı yalıtımı, ses yalıtımı ve akustik düzenleme için kullanılabilir. Yangın güvenliği hususunda en yaygın kullanılan malzemedir. Yoğunluğu kalınlığa da bağlı olarak $30-200 \mathrm{~kg} / \mathrm{m}^{3}$ arasında değișir. Isı iletkenlik değeri $0,040 \mathrm{~W} / \mathrm{mK}$, kullanım sicaklığı $-50^{\circ} \mathrm{C} /+750^{\circ} \mathrm{C}$ aralığındadır. Sicağa ve rutubete maruz kalmasi halinde boyutsal kararlığını korur. Zamanla bozulmaz, çürümez, küf tutmaz, korozyon ve pas yapmaz. Böcekler ve mikroorganizmalar tarafından tahrip edilemez. Higroskopik ve kapiler değildir [17-19].
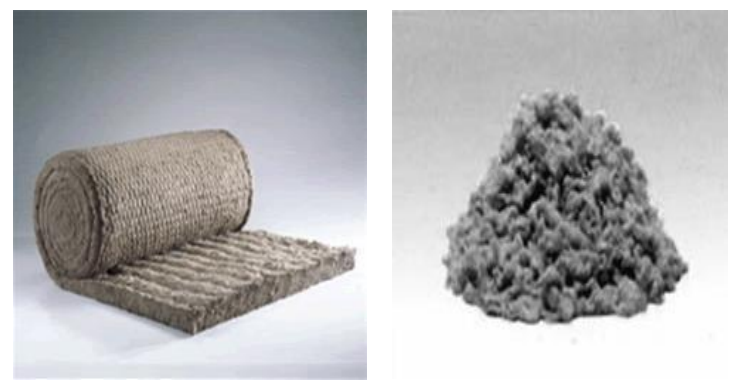

Şekil 2. Taş yünü $[17,18]$

\subsection{Ekstrüde Polistren Köpük (XPS)}

Polistren ham maddesinden ekstrüzyon yolu ile üretilmektedir. Kullanım yeri ve amacına göre farklı boyut ve basma mukavemetinde, değişik kenar ve yüzey şekillerinde levha olarak üretilebilmektedir. (Şekil 3). 20-52 kg/m yoğunlukları arasında üretilebilmektedir. Is1 iletkenlik değeri $0,035 \mathrm{~W} / \mathrm{mK}^{\prime}$ 'dir.

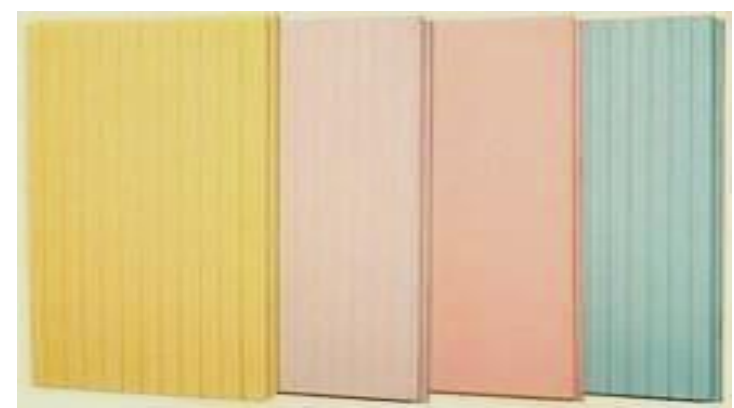

Şekil 3. Ekstrüde polistren (XPS) [19]

$\mathrm{Su}$ buharı difüzyon direnç faktörü 90-100 arasında değişir. Kullanım sıcaklığ 1 $50^{\circ} \mathrm{C} /+75^{\circ} \mathrm{C} \quad$ aralığındadır. $\% 100$ kapalı gözenekli homojen hücre yapısına sahip olup bünyesine su almamaktadır. Kapiler emiciliği yoktur ve basma dayanımı çok yüksektir. TS EN 1350-1'e göre E sinıfindadır [17-20]. 


\subsection{Genleştirilmiş Polistren Köpük (EPS)}

Polistren taneciklerinin şişirilmesi ve birbirine kaynaşması ile elde edilen ürünlerde taneciklerin şişirilmesi ve köpük elde edilmesi için kullanılan şişirici gaz pentandır. Pentan tanecikler içinde çok sayıda küçük gözeneklerin oluşmasını sağladıktan sonra üretim sırasında ve üretimi takiben çok kısa sürede hava ile yer değiştirir. Böylece genleştirilmiş polistren köpük levhaların bünyesinde bulunan çok sayıdaki küçük kapalı gözenekli hücreler içinde durgun hava hapsolur. Malzemenin \%98'i hareketsiz havadır. Mekanik dayanım şişirici gazın çok kısa sürede hava ile yer değiştirmesi ürünün performansının kullanım ömrü boyunca sabit kalmasını sağlar.

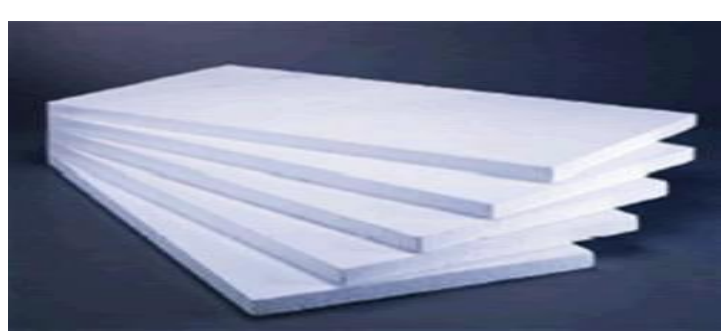

Şekil 4. Genleştirilmiş polistren köpük (EPS) [19]

Malzemenin üretiminin son aşaması olan kalıplamada taneciklerin birbiri ile sıkıca kaynaşması sağlanır. Bu uygulamanın başarısı ürünün yüzeyindeki taneciklerin bal peteği şeklindeki görüntüsünden anlaşılır (Şekil 4). Malzemenin hafif olması malzemenin diğer bir önemli özelliğidir.

Kullanım yeri amacına göre farklı boyut ve teknik özelliklerde değişik kenar ve yüzey şekillerinde levha ve kalıp olarak üretilebilmektedir. Isı yalıtımı ve ambalaj maksadıyla kullanılmaktadır. Güneşin mor ötesi ışınlarına karşı hassastır. Asit ve baz kimyasallara dirençli olmasına karşın baca gazları, metan grubu gazları, benzin grubu, eter, ester ve amin grubu kimyasallara karşı hassastır. $10-30 \mathrm{~kg} / \mathrm{m}^{3} \quad$ yoğunlukları arasında üretilebilmektedir. Isı iletkenlik değeri $0,040 \mathrm{~W} / \mathrm{mK}$, su buharı difüzyon direnci ise
20-100 arasındadır. Kullanım sıcaklığ $-50^{\circ} \mathrm{C} /+75^{\circ} \mathrm{C}$ aralığındadır. Kapiler emiciliği yoktur [17-19].

\subsection{Polietilen Köpük}

Kullanım yeri amacına göre farklı boyut ve teknik özelliklerde boru ve levha olarak üretilebilmektedir. Isı yalıtımı ve yoğuşma kontrolu maksadıyla kullanılmaktadır. (Şekil 5.) Isı İletkenlik beyan değeri $0,040 \mathrm{~W} / \mathrm{mK}$ 'dir. Su buharı difüzyon direnç faktörü $\mu>5000^{\prime}$ dir. Kullanım sıcaklığ $1-45^{\circ} \mathrm{C} /+80^{\circ} \mathrm{C}$ aralığındadır.
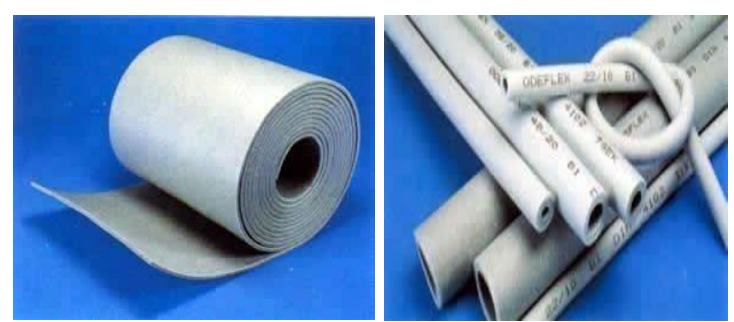

Şekil 5. Polietilen köpük [18]

Esnektir, kapalı gözeneklidir. Güneşin mor ötesi 1şınlarına karşı hassastır. 25-35 kg/m yoğunlukları arasında üretilmektedirler [17].

\subsection{Kauçuk Köpük}

Kullanım yeri amacına göre farklı boyut ve teknik özelliklerde boru ve levha olarak üretilebilmektedir. Isı yalıtımı ve yoğuşma kontrolu maksadiyla kullanılmaktadır. Is1 iletkenlik beyan değeri $0,038 \mathrm{~W} / \mathrm{mK}$ 'dır. Yoğunluğu $120 \mathrm{~kg} / \mathrm{m}^{3}$ tür. $\mathrm{Su}$ buharı difüzyon direnç faktörü $\mu>$ 3000-7000'dir. Kullanım sıcaklığ $1-60^{\circ} \mathrm{C} /+105^{\circ} \mathrm{C}$ aralığındadır. Esnektir. Kapalı gözeneklidir. Güneşin mor ötesi ışınlarına karşı hassastır [18-20].

\subsection{Fenol Köpüğü}

$100^{\circ} \mathrm{C}$ 'de kullanılabilen yanıcı ve yakıcı gaz çıkarmama, ayrışırken erimeme, alev iletmeme gibi özelliklere sahip olmasından dolayı sentetik köpükler arasında önemli bir yer alır. Genellikle çok sıcak ve çok soğuk koşullarda çalışan 
sistemlerde, soğuk depolarda ve düşük basınçlı buhar iletim borularında yalıtım amaçlı kullanılırlar (Şekil 6).

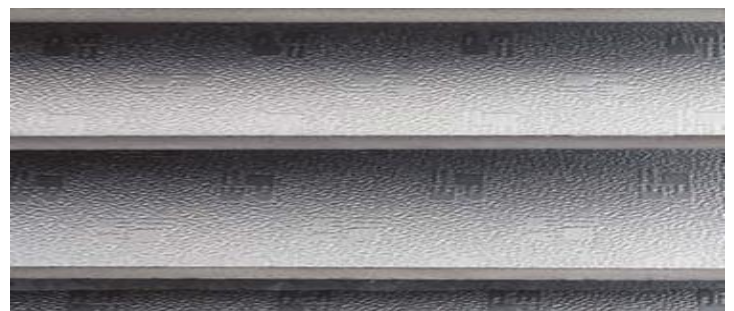

Şekil 6. Fenol köpüğü [19]

Is1 iletkenlik değeri $0,04 \mathrm{~W} / \mathrm{mK}$ değerindedir. Buhar difüzyon direnç katsayısı 10 ile 50 arasındadır. Kullanım sıcaklığ $1-180^{\circ} \mathrm{C}$ ile $120^{\circ} \mathrm{C}$ arasındadır. Yanma sinıfi BS 476 standardına göre $\quad 100-150 \quad \mathrm{kPa}$ arasında basınç mukavemetine sahiptir [18,19].

\subsection{Seramik Yünü}

Kullanım yeri amacına göre farklı boyut ve teknik özelliklerde rulo, dökme ve levha olarak üretilebilmektedir. Isı iletkenlik beyan değeri $0,040 \mathrm{~W} / \mathrm{mK}$ 'dir. Sicağa ve rutubete maruz kalması halinde dahi boyutsal kararlılığını korur. BS 476'ya göre yanmaz malzeme sınıfinda olduğundan yangın yalıtımı amacıyla da kullanılır. Kullanım sıcaklığı $1400{ }^{\circ} \mathrm{C}$ değerini bulmaktadır. Yoğunluğu $60-160 \mathrm{~kg} / \mathrm{m}^{3}$ arasında değişir (Şekil 7).

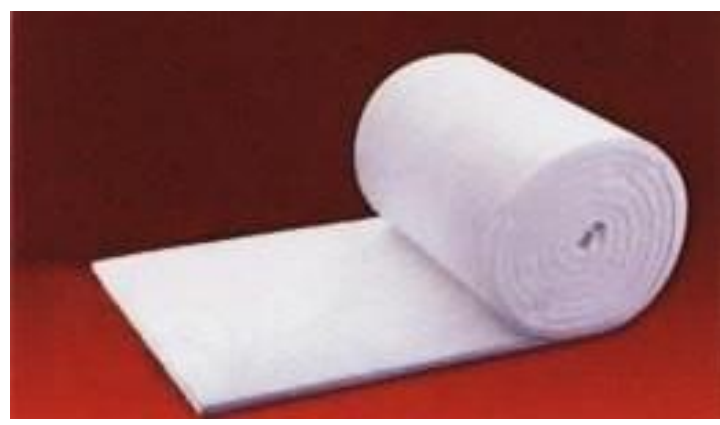

Şekil 7. Seramik yünü [19]

Maliyeti yüksek bir malzeme olmasından dolayı genellikle uygulama sıcaklığının taş yününün kritik sıcaklık değerlerini aştığı yerlerde tercih edilir. Higroskopik veya kapiler değildir. Beyaz renkli, elyaflı, kokusuz malzemedir $[18,19]$

Çizelge 1 - Çizelge 3'de gemilerde kullanılan yalıtım malzemeleri, yüzey alevlenme kıstasları ve döşeme kaplamalarına ait özellikler belirtilmiştir.

Çizelge 1. Gemilerde kullanılan yalıtım malzemeleri ve özellikleri

\begin{tabular}{|c|c|c|c|c|c|c|}
\hline 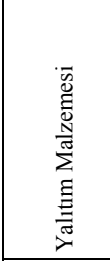 & 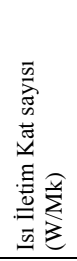 & 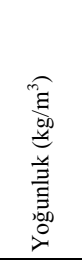 & 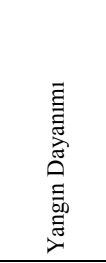 & 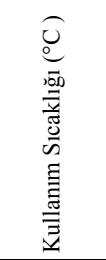 & 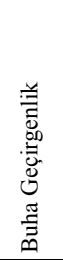 & 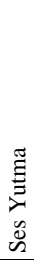 \\
\hline $\begin{array}{l}\text { Cam } \\
\text { yünü }\end{array}$ & 0,04 & $10 / 120$ & Yanmaz & $-50 / 250$ & 1 & + \\
\hline $\begin{array}{l}\text { Taş } \\
\text { yünü } \\
\end{array}$ & 0,04 & $30 / 200$ & Yanmaz & $-50 / 750$ & 1 & + \\
\hline $\begin{array}{l}\text { Ekstrüde } \\
\text { polistren }\end{array}$ & 0,035 & $20 / 52$ & $\begin{array}{c}\text { Alev } \\
\text { yürütmez }\end{array}$ & $-50 / 75$ & $\begin{array}{l}90 / \\
100\end{array}$ & - \\
\hline EPS & 0,04 & $10 / 30$ & Alev & $-50 / 75$ & $\begin{array}{l}20 / \\
100\end{array}$ & - \\
\hline $\begin{array}{l}\text { Polietilen } \\
\text { köpük }\end{array}$ & 0,04 & $25 / 35$ & $\begin{array}{c}\text { Alev } \\
\text { yürütmez }\end{array}$ & $-45 / 80$ & 5000 & - \\
\hline \begin{tabular}{|l} 
Kauçuk \\
köpük \\
\end{tabular} & 0,038 & 120 & $\begin{array}{c}\text { Alev } \\
\text { yürütmez }\end{array}$ & $-60 / 105$ & $\begin{array}{l}3000 / \\
7000 \\
\end{array}$ & - \\
\hline Poliüretan & $\begin{array}{l}0,025 \\
/ 0,035\end{array}$ & $30 / 40$ & $\begin{array}{c}\text { Alev } \\
\text { yürütmez }\end{array}$ & $-200 / 120$ & $40 / 50$ & - \\
\hline \begin{tabular}{|l} 
Fenol \\
köpügüü \\
\end{tabular} & 0,04 & $30 / 120$ & $\begin{array}{c}\text { Alev } \\
\text { yürütmez }\end{array}$ & $-180 / 120$ & $10 / 50$ & - \\
\hline $\begin{array}{l}\text { Seramik } \\
\text { yünü }\end{array}$ & 0,04 & $60 / 160$ & Yanmaz & $-50 / 1400$ & 1 & + \\
\hline
\end{tabular}

Çizelge 2. Ara bölme, duvarlar ve tavanda kullanılan malzemelerde düşük alev yayılım hızının belirlenmesi için yüzey alevlenme kıstasları [9]

\begin{tabular}{|c|c|c|c|}
\hline \multicolumn{4}{|c|}{ Ara Bölme, Duvarlar ve Tavan } \\
\hline $\begin{array}{c}\text { Kritik } \\
\text { Sönüm } \\
\text { Ak1s1 } \\
\left(\mathrm{kW} / \mathrm{m}^{2}\right)\end{array}$ & $\begin{array}{c}\text { Yanma } \\
\text { Is1s1 } \\
\left(\mathrm{MJ} / \mathrm{m}^{2}\right)\end{array}$ & $\begin{array}{c}\text { Açığa } \\
\text { Çıkan } \\
\text { Toplam } \\
\text { Isı } \\
(\mathrm{MJ})\end{array}$ & $\begin{array}{c}\text { Açı̆̆a } \\
\text { Çıkan En } \\
\text { Yüksek } \\
\text { Isı Oranı } \\
(\mathrm{Kw})\end{array}$ \\
\hline$>20,0$ & $>1,5$ & $<0,7$ & $<4,0$ \\
\hline
\end{tabular}

Yüksek miktarda duman ve zehirli yanma ürünleri açığa çıkarmama şartı için malzemeler IMO FTP'ye uygun olarak test edilmelidirler. Yanma sonucu ortaya çıkan yedi zehirli gaz bileşeni yoğunluğu ve konsantrasyonu için sınırlamalar ISO 5659-2:1994.6 ile belirtilmiştir. 
Çizelge 4'de bu yedi gaza ait müsaade edilen en yüksek konsantrasyon değerleri verilmiştir.

Çizelge 3. Döşeme kaplamalarında kullanılan malzemelerde düşük alev yayılım hızının belirlenmesi için yüzey alevlenme kıstasları [9]

\begin{tabular}{|c|c|c|c|}
\hline \multicolumn{4}{|c|}{ Döşeme Kaplamaları } \\
\hline $\begin{array}{c}\text { Kritik } \\
\text { Sönüm } \\
\text { Ak1s1 } \\
\left(\mathrm{kW} / \mathrm{m}^{2}\right)\end{array}$ & $\begin{array}{c}\text { Yanma } \\
\text { Is1S1 } \\
\left(\mathrm{MJ} / \mathrm{m}^{2}\right)\end{array}$ & $\begin{array}{l}\text { Açığa } \\
\text { Çıkan } \\
\text { Toplam } \\
\text { Isı (MJ) }\end{array}$ & $\begin{array}{c}\text { Açığa } \\
\text { Çıkan } \\
\text { En } \\
\text { Yüksek } \\
\text { Isı Oranı } \\
\text { (Kw) }\end{array}$ \\
\hline$>7,0$ & $>0,25$ & $<1,5$ & $<10,0$ \\
\hline
\end{tabular}

Çizelge 4. Gaz konsantrasyon sınırları [9]

\begin{tabular}{|ll|c|}
\hline \multicolumn{2}{|c|}{ Gaz } & $\begin{array}{c}\text { Gaz } \\
\text { Konsantrasyonu } \\
(\mathrm{ppm})\end{array}$ \\
\hline Karbon Monoksit & $(\mathrm{CO})$ & 1450 \\
\hline Hidroklorik Asit & $(\mathrm{HCL})$ & 600 \\
\hline Hidrojenflorik Asit & $(\mathrm{HF})$ & 600 \\
\hline Azot Oksit & $\left(\mathrm{NO}_{\mathrm{x}}\right)$ & 350 \\
\hline Hidrobromik Asit & $(\mathrm{HBr})$ & 600 \\
\hline Hidrosiyanik Asit & $(\mathrm{HCN})$ & 140 \\
\hline Sodyum Dioksit & $\left(\mathrm{SO}_{2}\right)$ & 120 \\
\hline
\end{tabular}

Yanıcı bağlayııı ve yapıştırıcılar mümkün olan en az miktarda kullanılmalı ve yangının ilk safhalarında yangına destek vermemelidirler. Yanıcı bağlayıcı ve yapıştırıcılar 1sı kaynaklarıyla direk temasta bulunmamalıdırlar [17].

\section{FORMÜLLER VE DENKLEMLER}

Yapısal elemanların yalıtımında kullanılacak yalıtım kalınlığını tespit etmek için ilk adım yalıtım yapılacak mahalin komşu mahal ya da dış hacim ile arasındaki sıcaklık farkını tespit etmek olacaktır. $\mathrm{Bu}$ değerler, Çizelge 5 ve Çizelge 6'da verilmiştir.

$\mathrm{Bu}$ verilerin deneysel veriler olması itibariyle; uygulayıcının benzer yapı elemanı boyutları, yapı elemanı yerleşimi, yalıtım malzemesi ve yalıtım uygulamalarında yapacağı hesaplarında bu verileri kullanması uygun olacaktır [18].

Çizelge 5. Müsaade edilen en yüksek toplam 1sı geçiş katsayısı değerleri [1]

\begin{tabular}{|c|c|}
\hline $\begin{array}{c}\text { Ortamlar Aras1 } \\
\text { Sicaklık Fark1 }\left({ }^{\circ} \mathrm{C}\right)\end{array}$ & $\begin{array}{c}\text { En yüksek U Değeri } \\
\left(\mathrm{W} / \mathrm{m}^{2} \mathrm{~K}\right)\end{array}$ \\
\hline $0-8,3$ & 9,94 \\
\hline $8,3-16,6$ & 2,10 \\
\hline $16,6-27,7$ & 1,48 \\
\hline 27,7 üzeri & 0,908 \\
\hline
\end{tabular}

Şekil 8'de tam olarak yalıtılan yapı bileşeninin 1s1 geçişi şematik olarak, Çizelge 6'da ise, güneş ve hava sıcaklıkları gösterilmiştir.

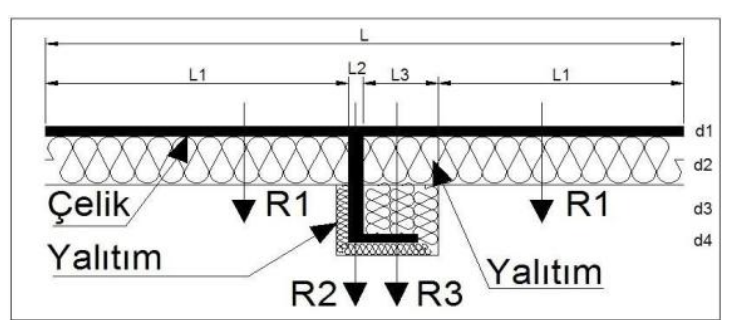

Şekil 8. Tamamen yalıtılmış yapı bileşeninden 1S1 geçişi [18]

Çizelge 6. Güneş-hava sıcaklıkları, Tb [18]

\begin{tabular}{|l|c|c|}
\hline $\begin{array}{l}\text { Güneşe Maruz } \\
\text { Yüzey Sayıs1 }\end{array}$ & $\begin{array}{c}\text { Düşey } \\
\text { Yönlü Isı } \\
\text { Geçişi }\end{array}$ & $\begin{array}{c}\text { Yatay } \\
\text { Yönlü Is1 } \\
\text { Geçişi }\end{array}$ \\
\hline Tek Yüzey & $52^{\circ} \mathrm{C}$ & $63^{\circ} \mathrm{C}$ \\
\hline Birden Fazla Yüzey & $46^{\circ} \mathrm{C}$ & $55^{\circ} \mathrm{C}$ \\
\hline
\end{tabular}

Sname [1], Isı Yalıtım Raporu'nda ise güneşhava sıcaklıklarının, tüm soğutma sezonu için yapılacak hesaplarda Çizelge 7'deki gibi alınmasını tavsiye etmiştir.

Türkiye için yüzeye dik gelen toplam güneş enerjisinin en yüksek değerinin soğutma sezonunda yaklaşı $800 \mathrm{~W} / \mathrm{m}^{2}$ olduğu düşünülürse, Çizelge 4'de verilen, Çizelge 5 ve Çizelge 6'nın ülkemiz şartlarında gelişmeler ile ortaya çıkan farklı yapı seçeneklerinden olan 1sı geçişinin hesabı için tasarımcının toplam 1s1 geçiş katsayısı değerlerini hesap etmesi 
gerekebilmektedir. Uygulayıcı bu değerleri hesap ederek uygulamada karşılaşılabilecek farkl1 ebatlardaki mukavemet elemanları, farklı yapı seçenekleri ve uygulanacak farklı yalıtım malzemeleri için uygulama yüzeyinden gerçekleşecek 1sı geçişini tespit edebilecektir $[1,6,7]$.

Çizelge 7. Sname Isı Yalıtım Raporu'nda verilen güneş-hava sıcaklıkları, $\mathrm{Tb}$ [1]

\begin{tabular}{|l|c|}
\hline Güneşe Maruz Yüzey & Yüzey Sıcaklığı \\
\hline $\begin{array}{l}\text { Çelik ve alüminyum } \\
\text { güverteler }\end{array}$ & $60^{\circ} \mathrm{C}$ \\
\hline Ahşap güverteler & $49^{\circ} \mathrm{C}$ \\
\hline Dikey metal yüzeyler & $49^{\circ} \mathrm{C}$ \\
\hline
\end{tabular}

Mukavemet elemanları ise kanat etkisi gösterdiklerinden ötürü üzerlerinden geçen 1s1 kanat hesabi ile bulunabilir. Gemilerde kullanılan mukavemet elemanları dikdörtgen kesitli kanat modeline uymaktadır. Bu durumda bir mukavemet elemanından gerçekleşen 1s1 transferi sınır şartları;

$Q_{m e}=\sqrt{h p A_{k}}\left(T_{i \zeta ̧}-T_{d \mathrm{lş}}\right) \frac{\sin _{h} m L+\frac{h}{m k} \cosh m L}{\cos _{h} m L+\frac{h}{m k} \sin _{h} m L}$

ifadesi ile verilir. Mukavemet elemanları uzunlamasına dikdörtgen kesitli kanat modeline uyduklarından, kanat kalınlığı kanat boyuna göre çok küçük kaldığından ve kanat ucu küçük bir alana sahip olup buradan gerçekleşen 1s1 geçişi ihmal edilebilir düzeyde küçük olduğundan denklem;

$Q_{m e}=k \cdot \delta \cdot L \cdot m \cdot \tan _{h} m b \cdot\left(T_{i c ̧}-T_{d \mathrm{~s} s}\right)$

ifadesi ile ya da;

$Q_{m e}=\sqrt{h \cdot p \cdot k \cdot A_{k}} \tan _{h} \cdot m b\left(T_{i c ̧}-T_{d \mathrm{lş}}\right)$

ifadesi ile hesaplanabilir. Burada;

$\mathrm{k}=$ Mukavemet elemanının 1sı iletim katsayısı $(\mathrm{W} / \mathrm{mK})$

$\mathrm{h}=$ Kanatçı̆̆ın bulunduğu ortamın 1sı taşınım katsayısı $\left(\mathrm{W} / \mathrm{m}^{2} \mathrm{~K}\right)$ $\delta=$ Mukavemet elemanının et kalınlığı (m)

$\mathrm{L}=$ Mukavemet elemanının genişliği (m)

$\mathrm{B}=$ Mukavemet elemanının boyu (m)

$\mathrm{P}=$ Mukavemet elemanı kesitinin çevre uzunluğu (m)

$\mathrm{Ak}_{\mathrm{k}}=$ Mukavemet elemanının kesitalanı $\left(\mathrm{m}^{2}\right)$

Mukavemet elemanlarının yapısı itibariyle $b \geq \delta$ yazılabilir. Yine buradan $\mathrm{m}$ değeri şu ifade ile hesaplanabilir: Verilen denklemler yardımıyla toplam 1s1 geçişi bulunur. Bulunan bu değerin toplam alan ve sicaklık farkına bölünmesi ile yüzey için toplam ısı geçiş katsayısı hesap edilir.

\section{SONUÇLAR}

Dünyada artan nüfus, gelişen teknoloji ve sanayi ile artan enerji ihtiyacı ve tükenmekte olan fosil kaynaklı yakıt rezervleri enerji tasarrufunu tüm sistemlerde zorunlu kılmaktadır. Bu çalışmada dünyada bu konuda yapılmış çalışmalar incelenerek gemilerin yapısal elemanlarının, gemilerdeki mekanik tesisatın ve soğuk depo ve konteynerlerin yalıtımı, malzeme seçimi, terleme ve yoğuşma kontrolü konuları ele alınarak hesap metotları açıklanmış ve tasarım kıstasları ülkemiz şartlarına uyarlanarak bir kılavuz oluşturulmuş, örnekler ile de anlatılanlar pekiştirilmeye çalışılmıştır.

Çalışmada, gemilerin düz yüzeylerinde ve mukavemet elemanlarından olan 1sı geçişinde, toplam 1sı geçiş katsayılarının tespiti için hesap yöntemleri verilmiştir. Bulunan değerler ile Sname Isı Yalıtım Raporu'nda verilen deney yoluyla elde edilmiş değerlerin örtüşmesi üzerine bu yayındaki değerlerin benzer koşullarda kullanılabileceği sonucuna varılmıştır. $\mathrm{Bu}$ değerler ülkemiz şartlarında işletilen bir gemi için yapılan uygulama örneğinde ele alınmış ve uygunluğu teyit edilmiştir. Borularda 1S1 kaybı ve yalıtım kalınlığı hesapları verilmiş, örneklerde elde edilen sonuçların ASTM standardındaki veriler ile örtüştüğü gözlenmiş, bu standarttaki verilerin ülkemiz şartlarında da kullanılabileceği sonucuna varılmıştır. Gemilerdeki mukavemet elemanları, gelişen teknoloji ile gemilerde 
kullanım amaciyla üretilen teknolojik malzemeler, gemilerde yangın ve ses yalıtımı, farklı gemi tiplerine göre çeşitlenen uygulama metotları, bu alanda öncelikli olarak araştırma konusu olarak ele alınabilecek bazı başlıklardır. Ülkemizde denizcilik faaliyetlerinin önemi ve gemi inşa sanayisinin büyüme hızı göz ardı edilmemeli, bu konuya gereken ilgi gösterilmelidir.

\section{TEŞEKKÜR}

Finansal desteklerinden dolayı Marmara Üniversitesi Sağlik, Kültür ve Spor Daire Başkanlığı'na teşekkürlerimizi sunarız.

\section{KAYNAKLAR}

1. Society of Naval Architects and Marine Engineers (SNAME), 1974. Thermal Insulation Report, Technical and Research Bulletin No. 4-7, New York.

2. ASTM-F683-03, 2004. Standard Practice for Selection and Application of Thermal Insulation for Piping and Machinery, American Society of Testing and Materials, International (ASTM), PA.

3. Military Sealift Command, 1997. General Technical RequirementsNo.22, US Navy, Washington D.C.

4. American Bureau of Shipping (ABS), 2001. Passanger Comfort on Ships, Houston, TX.

5. TS-825, 2008. Binalarda Is1 Yalıtım Kuralları, Türk Standartları Enstitüsü, Ankara.

6. Hart, G. 2004. Ship Configurations: Insulation Design and Application Insulation Outlook, National Insulation Association.

7. Fulton, P. Hart, G. Cox, G, 2005. Improved Thermal Insulation Design Practices on Ships' Structural Boundaries, Sname organization dated, New York. 06-22-05.

8. Cox, G. Curtin, M. 2008. Shipboard System Insulation Design - Using 3E Plus As an Integral Factor, Insulation Outlook, National Insulation Association.

9. Burton, G. 2006. Regulatory Requirements for Insulation Products in Marine
Applications, Insulation Outlook National Insulation Association.

10. Parmaksızoğlu, C. Özdemir, M. 2005. Mekanik Tesisatta Ekonomik Yalıtım Kalınlığı, Teskon, VII. Ulusal Tesisat Mühendisliği Kongresi, İzmir.

11. Parmaksızoğlu. C. Mayıs-Haziran 2005. Is1 Yalıtımının Amaçları ve Tesisatlarda S1caklık Düşmesi, İzolasyon Dergisi,

12. Kraus, A. Aziz, A. Welty, J. 2001. Extended Surface Heat Transfer, John Wiley \& Sons, Inc., New York.

13. Genceli, O. 1995. Isıtma Havalandirma ve İklimlendirme Yardımcı Tabloları, İstanbul Teknik Üniversitesi, İstanbul.

14. Ashrae. 1996. Isı Yalıtımı ve Buhar Kesiciler Temel El Kitabı (Fundamentals) / çev. Osman F. Genceli, Tesisat Mühendisleri Derneği, İstanbul.

15. http://www.shodb.gov.tr, 08.10.2015. Seyir, Hidrografi ve Oşinografi Dairesi Başkanlığı Resmi internet Sitesi.

16. DMI, 2009-2014 Yılları Arasında Türkiye Denizlerindeki İstasyonlarda Ölçülen En Düşük Sicaklık Değerleri, T.C. Çevre ve Orman Bakanlığı Devler Meteoroloji İşleri Genel Müdürlüğü Araştırma ve Bilgi İşlem Daire Başkanlığı İstatistik ve Yayın Şube Müdürlüğü, Ankara. 2015.

17.http://www.izocam.com.tr, İzocam A.Ş. Resmi internet sitesi.

18. http://www.sistembau.com

19. http://www.dkmyalitim.com

20. http://www.ode.com.tr 